\title{
Socio-Economic Determinants of Maternal Health Care Utilization in Kailahun District, Sierra Leone, 2020
}

\section{Desmond Kangbai}

Ghana Field Epidemiology and Laboratory Training Program, University of Ghana of School of Public Health, Legon, Accra

\section{Delia Akosua Bandoh}

Ghana Field Epidemiology and Laboratory Training Program, University of Ghana of School of Public Health, Legon, Accra

\section{Alexander Manu}

Department of Epidemiology and Disease Control, School of Public Health, University of Ghana, Legon Joetrice Kangbai

University of Leeds

\section{Ernest Kenu}

Ghana Field Epidemiology and Laboratory Training Program, University of Ghana of School of Public Health, Legon, Accra

Adolphina Addo-Lartey ( $\square$ aaddo-lartey@ug.edu.gh )

Department of Epidemiology and Disease Control, School of Public Health, University of Ghana, Legon

\section{Research Article}

Keywords: Determinants, Maternal healthcare, Healthcare utilization, Skilled birth attendant, Antenatal care, Postnatal care, Kailahun, Sierra Leone

Posted Date: January 25th, 2021

DOl: https://doi.org/10.21203/rs.3.rs-139307/v1

License: (c) (i) This work is licensed under a Creative Commons Attribution 4.0 International License. Read Full License

Version of Record: A version of this preprint was published at BMC Pregnancy and Childbirth on April 1st, 2022. See the published version at https://doi.org/10.1186/s12884-022-04597-z. 
1 Socio-economic determinants of maternal health care utilization in Kailahun District,

2 Sierra Leone, 2020

3 Desmond Maada Kangbai ${ }^{1}$, Delia Bandoh ${ }^{1}$, Alexander Manu ${ }^{2}$, Joetrice Yewah Kangbai ${ }^{3}$, 4 Ernest Kenu ${ }^{1}$, and Adolphina Addo-Lartey ${ }^{2 *}$

5

6

$7 \quad{ }^{1}$ Ghana Field Epidemiology and Laboratory Training Program, University of Ghana of School

8 of Public Health, Legon, Accra

$9 \quad{ }^{2}$ Department of Epidemiology and Disease Control, School of Public Health, University of

10 Ghana, Legon,

$11{ }^{3}$ Healthcare Nursing University of Leeds, Leeds.

12

13

14 *Corresponding author: aaddo-lartey@ug.edu.gh

15 School of Public Health, University of Ghana, Legon

16 
BACKGROUND: Ascertaining the key determinants of maternal healthcare service utilization and their relative importance is critical to priority setting in policy development.

Sierra Leone has one of the world's highest maternal death ratios in the context of a weak health system. The objectives of this study were to determine; the level of utilization of Antenatal Care (ANC), Skilled Delivery Attendants (SDA), Postnatal Care (PNC) services, and factors that influence the utilization of these services.

METHODS: We conducted a community-based cross-sectional study involving 554 women of reproductive age (15-49 years) who had at least one delivery in the last 3 years and lived in the Kailahun District, Sierra Leone from November 2019 to October 2020. Stata IC version 15.0 was used to analyse factors affecting maternal care utilization use.

RESULTS: The median age of respondents was 25 years $(\mathrm{Q} 1=17$ years, $\mathrm{Q} 3=30$ years $)$. Eightynine percent $(89 \%)$ had 4 or more ANC visits. Only $35.9 \%$ of women were delivered by SDA. Women residing in urban areas had over six-fold increased odds of utilizing SDA as compared to women residing in rural areas $(\mathrm{AOR}=6.20,95 \% \mathrm{CI}=3.61-10.63)$. Women whose husbands had a primary level of education had 2.38 times increased odds of utilizing SDA than women whose husbands had no education $(\mathrm{AOR}=2.38,95 \% \mathrm{CI}=1.30-4.35)$. Women that walked longer distances (30-60 minutes) to seek healthcare had 2.98 times increased odds of utilizing SBA than those that walked shorter distances ( $<30$ minutes) $(\mathrm{AOR}=2.98,95 \% \mathrm{CI}=1.67-5.33)$. Women who had a secondary/vocational level of education had 2.35 times increased odds of utilizing the standard PNC category as compared to those with no education (OR=2.35, 95\% $\mathrm{CI}=1.19-4.63)$.

CONCLUSION: The majority of women had 4 or more ANC visits yet the use of skilled birth attendants was low. Urban residence and education were significantly associated with the use

41 of the standard PNC category. Education level and occupation of women, Husband's education, urban residence, and longer distance to health facilities were significant determinants of SDA 
43 use. To improve the utilization of maternal health care services, national healthcare policies

44 should target the advancement of education, rural infrastructure, and the empowerment of 45 women.

46

47

48 Keywords: Determinants, Maternal healthcare, Healthcare utilization, Skilled birth attendant, 49 Antenatal care, Postnatal care, Kailahun, Sierra Leone

50

51 
53 Maternal health care (MHC) utilization is essential for women's health, childbirth, and the 54 well-being of the mother and child. Maternal health care includes the care a woman receives throughout her pregnancy, labor, and postnatal [1]. The World Health Organisation has set a goal in alignment with the $3^{\text {rd }}$ Sustainable Development Goals (SDG) which aims to reduce the global maternal mortality ratio (MMR) to less than 70 per 100,000 live births by 2030 " [2]. Ascertaining the determining factors of maternal health care utilization and how these factors affect the livelihood of mothers is critical and must be a priority in policy development [3]. Research suggests that there is a high prevalence of maternal, neonatal, and child death rates which are linked to non- or poor availability of quality maternal healthcare services $[4,6]$. The evidence also indicates that accessing skilled care before, throughout pregnancy, and after delivery saves the lives of mothers and their new-born child infants $[4,5]$. If mothers have access to healthcare facilities that provide interventions and preventive measures to treat obstetric complications, especially in an emergency, then an estimated $74 \%$ of maternal mortality could be prevented [6]. Antenatal care, skilled delivery attendants, and postnatal care attendants are therefore identified as key providers to improve health outcomes for mothers and their babies [7]. Studies in Ethiopia, Ghana, and Cambodia showed similar findings [4, 8, 69 9].

In Sub-Saharan Africa, the factors that influence the increase in maternal mortality are also associated with prenatal care coverage and skilled attendance at delivery. The inability to utilize these maternal healthcare services is a key predictor of perinatal mortality [2]. Regular antenatal care (ANC) attendance throughout the pregnancy enables the healthcare providers to have a better chance to detect and reduce any risk factors associated with adverse pregnancy outcomes [10]. The ANC session further serves as a platform to counsel the mothers' on why a skilled attendant is crucial at delivery [11]. Only $45 \%$ of women used skilled delivery 
In Sierra Leone, data from the past five years shows that approximately, $83 \%$ of births occurred in a health care facility; $81 \%$ occurred in government healthcare centers, $2 \%$ in a private health setting, $16 \%$ at home, and $1 \%$ in other places like in-transit or secret society bushes [12]. About $87 \%$ of deliveries are attended by a skilled attendant; $81 \%$ were attended by a nurse/midwife, $2 \%$ by an $\mathrm{MCH}$ Aide, and $4 \%$ by a doctor. On the other hand, $10 \%$ of childbirths are supervised by traditional birth attendants and $3 \%$ by family members or others [12]. Similarly, $79 \%$ of mothers received at least 4 antenatal care visits during their pregnancy and 14\% of mothers did not receive any postnatal check-ups [12].

Globally, 810 women die per day owing to pregnancy-related complications [13]. Maternal death remains a great concern with virtually $99 \%$ of all maternal deaths occurring in developing nations, but the prevalence is higher in Sub-Saharan Africa [14]. One in 41 pregnant women died during childbirth in developing countries as compared to 1 in 3,300 in developed nations [14]. "Sierra Leone has one of the world's highest maternal death ratios at 1360 deaths per 100000 babies born. WHO estimated that up to $6 \%$ of women in Sierra Leone will die from maternal causes during their reproductive life" [2]. The use of maternal health care services are known to better health outcomes for mothers and their children [15]. What is unclear is how service utilization is affected by socio-demographic and economic factors within which the women live especially in Sierra Leone and particularly in the Kailahun district which is one of the farthest from the national capital and the hub of the civil conflict in 1991. There are limited researches that identify factors influencing the utilization of MHC services in Kailahun District, Sierra Leone. The Sierra Leone Demographic and Health Survey (SLDHS) does not address factors influencing utilization and other previous studies conducted in Sierra Leone focused on one or two of the components of MHC service $[16,17]$. This research sought to investigate the socio-economic factors that influence women's use of maternal healthcare services in Eastern Sierra Leone with a focus on prenatal, delivery care, 
103

104

105

106

107

108

109

\section{METHODS}

\section{Study design, population, and setting}

112 We conducted a community-based cross-sectional study that involved women of reproductive 113 age (15-49 years), who had at least one delivery in the 3 years before this study in the Kailahun

114 District, Eastern Sierra Leone from November 2019 to October 2020. Kailahun District is

115 located about 450 kilometers from Freetown ( the capital) in the Eastern province of Sierra

116 Leone. Its capital and largest city is the town of Kailahun. It is divided into 15 chiefdoms.

117 Healthcare facilities are divided into 15 community health centers (CHC), 52 community

118 health posts (CHP), 17 maternal child health posts (MCHP), 3 government hospitals, and 2

119 private clinics. The total projected population for 2020 is 625,500 (Statistics Sierra Leone,

120 2015). The total fertility rate is estimated at 6 children per woman (Statistics Sierra Leone,

121 2015). The ANC attendance for ANC1 and ANC4+ was 15,656 and 13,785 respectively [2].

122 The District of Kailahun shares borders with the Republic of Liberia to the East, and 123 the Republic of Guinea to the North.

\section{Sampling method}

Kailahun District was purposively selected. Administratively, Kailahun is divided into 15

127 Chiefdoms. Each Chiefdom is subdivided into sections. Each section is subdivided further into

128 Enumeration Areas (EAs). EAs are in administrative sections without overlapping into other 
sections. The unique identifier is the EA code. The domain of this study is the Urban and Rural

130 areas of Kailahun District. The 2015 census EAs were used as the Primary Sampling Unit

131 (PSU). The sample was selected from the frame of PSUs. Kailahun district has 891 EAs of

132 which 276 are urban and 615 rural. The total number of households (HH) in the Kailahun

133 district was 83,348, of which 57,316 are rural and 26,032 are urban The average households

134 per urban and rural EAs were 94 and 93 respectively. The proportional allocation of HH in the

135 Kailahun District concerning the domain was 69\% rural and 31\% urban.

136 The sample size was determined using Cochran's formula [18] with the following assumptions:

137 the estimated proportion ( $p$ ) of births by SBA was 0.6 , the estimated proportion of births by an 138 unskilled attendant $(q)$ was 0.4 , and a design effect (DEFF) of 1.5 from a previous study 139 conducted in Sierra Leone [12]. The level of precision $(d)$ was 0.05, and a 95\% CI (z) was 1.96, 140 were used to obtain a sample size of 554.

$$
\mathrm{n}=\frac{z^{2} p q}{d^{2}} \mathrm{XDEFF}
$$

142 To allocate the sample, we considered the precision of the domain level i.e. urban and rural 143 areas of Kailahun. To have a safe weighting sample, we allocated the 554 households 144 proportionately to the urban and rural areas. The EAs were selected using Probability to 145 Proportion size. The first sampling number was the product of the random number (r) and the 146 sampling interval. The sampling interval was the total HH divided by the number of EAs to be

147 selected. The first sampling number was used in selecting the EAs using PPS. A Random-walk 148 technique was used in selecting households/respondents. The first author facing east walked 149 into the center of the EA and randomly selected the third house from his right-hand side with 150 a definite pattern of selecting the 3, 6, 9, etc till we achieved the required number of households.

151 The choice of selecting the interval 3, 6, and 9 depended on the size of the EA. The smaller 152 the EA, the shorter the interval vice versa. Upon arrival in the $\mathrm{HH}$ only one eligible female 15 15349 years had given birth in the past 3 years before this study was enrolled. If no eligible in a particular $\mathrm{HH}$, we continued with the pattern of selecting the $\mathrm{HH}$. 


\section{Data collection technique and tools}

The primary data was collected using a structured and pre-tested questionnaire. Antenatal cards and hospital record books mothers had were inspected to confirm the information provided by women during the interview. The questionnaire was written in English and was adapted from the Standard Sierra Leone DHS Questionnaires [12].To ensure quality data, interviewers were trained, a pre-test was performed before the actual data collection. The interviewers were frequently supervised by the principal investigator during data collection and interviews were done in local languages.

\section{Operational definitions}

- Skilled delivery attendant: professionals with midwifery skills including Doctors, midwives, community health officers $(\mathrm{CHO})$.

- Antenatal care: This is the routine health control of presumed healthy pregnant women without symptoms, to diagnose diseases or complicating obstetric conditions without symptoms, and to provide information about lifestyle, pregnancy, and delivery. Pregnancy services are provided by health professions (Nurses, Doctors, CHOs, and Midwives).

- Postnatal care: services provided to women within 42 days after delivery by health professionals (Nurses, Doctors, CHOs, and Midwives).

\section{Outcome variables}

A set of questions on maternal healthcare, covering place of delivery, delivery attendant, place of PNC, PNC attendant, the timing of the first postnatal visit, follow-up after discharge, and place of follow-up after discharge were asked. For the purposes of the study, the outcome variable which was utilization of maternal health care services was assessed by two services:

- Skilled Delivery Attendant use (yes/no)

- Postnatal care service (Standard, Average and Undesirable) : 
1. Standard category: PNC from a skilled provider in a health facility within 1 hour after delivery; had at least one follow-up after discharge.

2. Average category: PNC from a non-skilled provider in a health facility within 1 hour after delivery and had at least one follow-up after discharge or PNC from a skilled provider but did not receive any of the other components- health facility delivery; no follow-up after discharge.

\section{Independent variables}

190 Andersen's behavioral model was adopted to determine the influence or effect of the independent variables (predisposing and enabling factors) on the utilization of maternal health services $[18,20]$. The predisposing factors were; age, women's education, parity, ethnicity, religion, marital status, occupation, number of births in the last 5 years, number of children

194 alive, and the enabling factors were; husbands education, residence, distance to the health

195 facility, type of floor and toilet.

198 The data were entered into MS Excel 2018 and cleaned. The analysis was done using Stata

199 15.0 IC. Description of the Predisposing and Enabling characteristics was first done, followed 200 by a description of the components/patterns of antenatal care, perinatal care/skilled delivery attendant, and postnatal care using frequencies, tabulations, and proportions. Bivariate analysis was done to determine the level of utilization of Maternal Healthcare services (Antenatal care,

203 Skilled delivery attendant, and Postnatal care services).

204 In the case of a skilled delivery attendant, a dichotomous dependent variable was constructed 205 to indicate whether or not the woman used services from a skilled provider. Because the 206 indicator is dichotomous, a logistic regression model was used. Bivariate and multivariate 
analysis techniques were used to estimate the nature of association and magnitude between dependent variables and independent variables (Individual and Enabling factors).

$$
\log \left[\frac{p i 2}{p i 1}\right]=\beta_{0}+\beta_{1} X_{i j}+\beta_{2} Y_{i j}+\cdots .+\epsilon 1_{i j}
$$

210 The outcome variable is the $\log$ odds that individual $i$ chose alternative $j$ relative to 1 , where

211 alternative 1 is the non-use of a skilled delivery attendant and 2 is the use of a skilled provider.

212 The independent variables are classified into individual and enabling factors represented by X

213 and $\mathrm{Y}$ respectively. $\epsilon 1$ follows a logistical distribution and represents the unobserved

214 determinants of antenatal care or postnatal care.

215 Initially, a simple binary logistic model was run for each independent variable against the 216 outcome variable. All independent variables that showed a significant association at $\mathrm{p}<0.05$

217 were included in the multivariate binary regression model. The P-value, crude odds ratios

218 (COR), adjusted odds ratios (AOR), and 95\% confidence interval were estimated.

219 For postnatal care services as a dependent variable, a trichotomous variable was constructed;

220 the standard PNC service category, average PNC service category, and the undesirable PNC 221 service category. Since the variable is trichotomous, the multinomial logistical regression 222 model was estimated.

$$
\log \left[\frac{p i j}{p i 1}\right]=\alpha_{0}+\alpha_{1 j} X_{i j}+\alpha_{2 j} Y_{i j}+\cdots+\epsilon_{2 i j}
$$

224 The outcome variable was the $\log$ odds that individual $i$ chose PNC service alternative $j(\mathrm{j}=2,3)$ relative to 1 , where alternative 1 was the standard PNC service category, 2 was the average PNC service category and 3 was the undesirable PNC service category. The independent variables are classified into individual and enabling factors represented by $\mathrm{X}$ and $\mathrm{Y}$ respectively. $\epsilon 2$ represents the unobserved determinants of birth delivery alternative.

\section{Ethical clearance}

Ethical approval was obtained from the Sierra Leone Ethics and Scientific Review Committee

232 (October 2019). Permission was also sought from the Kailahun Regional Health Directorate. 
233 Informed consent was obtained from the respondents. For respondents below 18 years, consent

234 was granted by the parent or guardian and assent sought from respondents. They were assured 235 of confidentiality and informed on the purpose of the study. The information was stored 236 without the names of the respondents in a folder that is only accessible to the research team.

237 For participants who could not read, the consent was read and explained to them in the presence 238 of an impartial witness or stakeholder in the community. All study methods were carried out 239 in accordance with relevant guidelines and regulations 


\section{RESULTS}

242

243

244

245

246

247

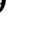

\section{Enabling and Predisposing/individual characteristics of respondents}

Five hundred and fifty-four (554) women aged between 15-49 years, who had at least a delivery/birth 3 years before this study commenced were interviewed. The median age of respondents was 25 years with minimum and maximum ages of 15 and 49 years respectively (Table 1). Taking into consideration parity, the median parity was 3 with a minimum and maximum parity of 1 and 9 respectively. Forty-six percent (46\%) of respondents in this survey were between the ages of $25-35$ years and $37.9 \%$ had no educational level. The majority $(60.8 \%)$ of respondents were Muslims. The Mende ethnic groups was predominant, (72\%).

\section{The components of ANC, skilled delivery, and PNC utilization}

The majority of women $(77.6 \%$; 430/554) have had ANC from a skilled provider. Most of the women $(57.9 \%$; 321/554) received ANC from a State Enrolled Community Health Nurse (SECHN). Regarding the timing of the first ANC visit, $(54.5 \%$; 302/554) of respondents attended their first ANC visit in the first trimester. The majority of respondents $(88.6 \%$; 491/554) had 4 or more ANC visits in their last pregnancy before this study. (Table 2)

(1)

(1)

(1)

(1)


269 Table 2 Characteristics of MHC service utilization by respondents who had at least one

270 delivery in the 3 years before the study, Kailahun District, 2020

\begin{tabular}{|c|c|c|}
\hline Variable & Number $(n=554)$ & Percent $(\%)$ \\
\hline \multicolumn{3}{|l|}{ At least one ANC from Skilled Provider } \\
\hline No & 124 & 22.4 \\
\hline Yes & 430 & 77.6 \\
\hline \multicolumn{3}{|l|}{ ANC Provider } \\
\hline Traditional Birth Attendant & 26 & 4.7 \\
\hline MCHA & 98 & 17.7 \\
\hline Midwife & 100 & 18.1 \\
\hline Doctor & 2 & 0.4 \\
\hline Nurse & 321 & 57.9 \\
\hline $\mathrm{CHO}$ & 7 & 1.3 \\
\hline \multicolumn{3}{|l|}{ Timing of First ANC } \\
\hline Don’t Know & 15 & 2.7 \\
\hline$<4$ months & 302 & 54.5 \\
\hline 4-6 months & 234 & 42.2 \\
\hline 7-9 months & 3 & 0.5 \\
\hline \multicolumn{3}{|l|}{ Number of ANC visit } \\
\hline Do not know & 5 & 0.9 \\
\hline Once & 4 & 0.7 \\
\hline 2 times & 11 & 2.0 \\
\hline 3 times & 43 & 7.8 \\
\hline 4 or more & 491 & 88.6 \\
\hline \multicolumn{3}{|l|}{ Skilled Delivery Attendant } \\
\hline No & 355 & 64.1 \\
\hline Yes & 199 & 35.9 \\
\hline \multicolumn{3}{|l|}{ Delivery Attendant } \\
\hline TBA (health facility/ community) & 23 & 4.2 \\
\hline Nurse & 13 & 2.3 \\
\hline MCHA & 319 & 57.6 \\
\hline Midwife & 177 & 31.9 \\
\hline Doctor & 22 & 4.0 \\
\hline \multicolumn{3}{|l|}{ Place of Delivery } \\
\hline MCHP & 58 & 10.5 \\
\hline CHP & 199 & 35.9 \\
\hline $\mathrm{CHC}$ & 198 & 35.7 \\
\hline Hospital & 75 & 13.5 \\
\hline Private Facility & 20 & 3.6 \\
\hline Home & 3 & 0.5 \\
\hline Ambulance/Transit & 1 & 0.2 \\
\hline \multicolumn{3}{|l|}{ Postnatal Care } \\
\hline Yes & 540 & 97.5 \\
\hline No & 14 & 2.5 \\
\hline
\end{tabular}




\section{Socio-demographic characteristics and the use of MHC}

272 The level of utilization of skilled ANC attendants was more common among respondents aged

$273>35$ years compared to the other age groups. In general, the use of skilled ANC attendants was

274 more than $75.0 \%$ in all age groups. With regards to parity, as the parity increased the use of 275 skilled ANC attendants decreased, women with one parity used more skilled ANC attendants 276 (79.6\%; 105/132) compared with 77.4\% (102/132) of women with 2 to 4 births and $76.2 \%$ of women with 5 or more births.

The use of SDA was found to be higher $(42.1 \%$; 32/76) amongst women in the age group of 10-19 years old compared with $36.1 \%$ (62/172) of women in the age group 20-24 years old, $35.4 \%(90 / 254)$ of those in the age group 25-35 years old, and $28.9 \%(15 / 52)$ in those older than 35 years.

Similar to ANC use, the use of skilled birth attendants decreased as the parity increased, $43.2 \%$ (57/132) of women who had 1 parity used skilled birth attendants compared with $37.3 \%$ (226/292) of those who had 2-4 parities and $25.4 \%$ of those who had 5 or more births. The utilization of PNC services was slightly higher amongst women in the age group 20-24 years compared with the other age groups. In contrast to ANC and skilled birth attendant use, PNC service use was slightly higher $(97.9 \% ; 372 / 381)$ among women in rural areas than women in urban areas $(96.5 \% ; 167 / 173)($ Table 3).

\section{Background characteristics influencing the use of a skilled delivery attendant}

Parity was significantly associated with the use of skilled birth attendants (Table 4). Women who had given birth 5 or more times had $55 \%$ reduced odds of been delivered by a skilled attendant as compared to those with 1 birth $(\mathrm{COR}=0.45,95 \% \mathrm{CI}=0.27-0.76)$. However, after controlling for the effect of the other variables, parity was not significantly associated with skilled birth attendant use. Women who had a senior secondary or vocational level of education had 1.22 times increased odds of been delivered by a skilled attendant as compared to those 
with no educational level which was statistically not significant after controlling for the effect of other variables $(\mathrm{AOR}=1.22,95 \% \mathrm{CI}=0.57-2.59)$. Women residing in urban areas had over

300 six-fold increased odds of been delivered by a skilled attendant as compared to women residing

301 in rural areas. This association remained statistically significant even after controlling for the

302 effect of the other variables $(A O R=6.20,95 \% \mathrm{CI}=3.61-10.63)$. Women whose husbands had a primary level of education also had 2.38 times increased odds of using skilled birth attendants than women whose husbands had no education. This association was also statistically significant even after controlling for the effect of the other variables in the model $(A O R=2.38$, $95 \% \mathrm{CI}=1.30-4.35)$.

\section{Background characteristics influencing the use of postnatal care services}

The level of education of a woman, residence, and the husband's education level were significantly associated with the use of the standard PNC category relative to the average category after controlling for the effect of the other variables in the model (Table 5). Women who had a secondary/vocational level of education had 2.35 times increased odds of utilizing the standard PNC category as compared to those with no education relative to the average PNC category $(\mathrm{OR}=2.35,95 \% \mathrm{CI}=1.19-4.63)$. Women's residence was significantly associated with the use of the standard PNC category relative to the average category. Women residing in urban areas had 2.29 times increased odds of utilizing the standard PNC category as compared to those residing in rural areas $(\mathrm{OR}=2.29,95 \% \mathrm{CI}=1.21-4.32)$. Husband's education was significantly associated with the use of the standard PNC category relative to the average category. Women whose husbands had a primary level of education had 2.36 times increased odds of utilizing the standard PNC category as compared to those whose husbands had no education relative to the average $\mathrm{PNC}$ category $(\mathrm{OR}=2.36,95 \% \mathrm{CI}=1.10-5.05)$. 
324 Table 1 Multinomial logistic regression results on the determinants of PNC services,

325 Kailahun District, Sierra Leone, 2020

\begin{tabular}{|c|c|c|c|c|c|c|c|}
\hline \multirow{3}{*}{$\begin{array}{l}\text { Variables } \\
\text { Age (Continuous) }\end{array}$} & \multirow{3}{*}{$\begin{array}{l}\begin{array}{l}\text { Number } \\
(\mathrm{n}=554)\end{array} \\
554\end{array}$} & \multicolumn{3}{|c|}{ Standard PNC } & \multicolumn{3}{|c|}{ Undesirable PNC } \\
\hline & & \multicolumn{2}{|c|}{ OR(95\% CI) } & \multirow{2}{*}{$\begin{array}{l}\text { P- } \\
\text { Value } \\
0.199\end{array}$} & \multicolumn{2}{|c|}{ OR(95\% CI) } & \multirow{2}{*}{$\begin{array}{l}\text { P- } \\
\text { Value } \\
0.923\end{array}$} \\
\hline & & $1.04(0.98$ & 1.10) & & $0.99(0.88$ & 1.12) & \\
\hline Parity & 554 & $0.69(0.38$ & $1.24)$ & 0.215 & $1.15(0.34$ & $3.90)$ & 0.818 \\
\hline \multicolumn{8}{|l|}{ Residence } \\
\hline Rural & 381 & 1.00 & & & 1.00 & & \\
\hline Urban & 173 & $2.29(1.21$ & $4.32)$ & $0.011 *$ & $1.59(0.37$ & $6.79)$ & 0.535 \\
\hline Marital Status & 554 & $0.82(0.38$ & $0.76)$ & 0.617 & $1.09(0.15$ & $7.80)$ & 0.933 \\
\hline \multicolumn{8}{|l|}{ Religion } \\
\hline Christian & 217 & 1.00 & & & 1.00 & & \\
\hline Islam & 337 & $0.71(0.41$ & $1.23)$ & 0.220 & $1.99(0.43$ & $9.14)$ & 0.375 \\
\hline \multicolumn{8}{|l|}{ Ethnicity } \\
\hline Others & 399 & 1.00 & & & 1.00 & & \\
\hline Mende & 124 & $1.23(1.23$ & $0.67)$ & 0.720 & $0.31(0.05$ & 1.91) & 0.207 \\
\hline Kissi & 31 & $0.62(0.18$ & 2.13) & 0.453 & $0.26(0.02$ & $2.76)$ & 0.263 \\
\hline \multicolumn{8}{|l|}{ Occupation } \\
\hline Employed & 433 & 1.00 & & & 1.00 & & \\
\hline Unemployed & 121 & $1.13(0.61$ & 2.11) & 0.689 & $4.04(0.46$ & 35.88) & 0.210 \\
\hline \multicolumn{8}{|l|}{ Education level attainment } \\
\hline None & 210 & 1.00 & & & 1.00 & & \\
\hline Primary & 142 & $1.10(0.55$ & 2.22) & 0.780 & $0.35(0.06$ & $1.90)$ & 0.224 \\
\hline Secondary/Vocational & 202 & $2.35(1.19$ & 4.63) & $0.013 *$ & $0.89(0.21$ & $0.69)$ & 0.872 \\
\hline \multicolumn{8}{|c|}{ Number of Births in past 5 years } \\
\hline 1 & 265 & 1.00 & & & 1.00 & & \\
\hline $2+$ & 289 & $1.02(0.56$ & 1.84) & 0.958 & $0.90(0.26$ & $3.10)$ & 0.867 \\
\hline \multicolumn{8}{|c|}{ Husband's Education level attainment } \\
\hline None & 238 & 1.00 & & & 1.00 & & \\
\hline Primary & 72 & $2.36(1.10$ & $5.05)$ & $0.027 *$ & $1.73(0.30$ & 9.97) & 0.537 \\
\hline Junior Secondary & 109 & $1.88(0.96$ & $3.69)$ & 0.064 & $1.09(0.20$ & $6.06)$ & 0.923 \\
\hline Senior Secondary & 82 & $0.81(0.35$ & $1.85)$ & 0.610 & $1.27(0.20$ & $8.06)$ & 0.802 \\
\hline Vocational/Higher & 53 & $2.29(1.03$ & $5.12)$ & $0.042 *$ & $4.07(0.77$ & 21.51) & 0.098 \\
\hline \multicolumn{8}{|c|}{ Distance to Health Facility (Minutes) } \\
\hline$<30$ & 196 & 1.00 & & & 1.00 & & \\
\hline $30-60$ & 132 & $1.36(0.71$ & $2.62)$ & 0.357 & $0.61(0.10$ & $3.55)$ & 0.580 \\
\hline$>60$ & 226 & $1.42(0.72$ & $2.81)$ & 0.312 & $0.82(0.19$ & $3.66)$ & 0.802 \\
\hline \multicolumn{8}{|l|}{ Type of Floor } \\
\hline Natural & 394 & 1.00 & & & 1.00 & & \\
\hline Modern & 160 & $1.35(0.80$ & 2.27) & 0.266 & $0.49(0.12$ & 1.99) & 0.318 \\
\hline
\end{tabular}

$326 *$ Significant association at $\mathrm{P}<0.05, \mathrm{n}=554$, pseudo $\mathrm{R}^{2}=8.81 \%$, LR Chi2 $=54.37$

327 Prob. Chi2 $=0.025$, Base model $=$ Average category

328 


\section{DISCUSSION}

This study assessed the level of utilization and determinants of ANC, skilled birth attendant, and uptake of the different packages of PNC services in Kailahun District Sierra Leone. This study found that $100.0 \%$ of women received ANC services, of which $77.6 \%$ of them sought at least one ANC visit from a skilled ANC provider and $88.6 \%$ made 4 or more ANC visits as recommended by the World Health Organization. These findings are similar to reports in the Sierra Leone Demographic and Health Survey which showed that $98.0 \%$ of women received ANC from a skilled provider and 79.0\% made 4 or more ANC visits [12]. However, our results are also inconsistent with the Uganda Demographic and Health Survey UDHS 2016, which showed that $97.0 \%$ of women received ANC from a skilled provider but only $60.0 \%$ of the women made 4 or more ANC visits [25]. The disparity between the present study and the UDHS may be related to the maternal demographic characteristics in both countries and the fact that the sample size in the UDHS was far larger, thus influencing the precision of the findings.

Regarding the timing of the first ANC, 54.5\% of women sought their first ANC in the first trimester of pregnancy and this prevalence was higher than that obtained in the Sierra Leone Demographic and Health Survey 2019, where 44.0\% made their first visit in the first trimester [12]. This discrepancy could be attributed to the demographic survey having had a larger coverage area as compared to the present study. It has been recommended that all pregnant women should start their ANC in the first trimester [26]. The findings of this research suggest that the use of ANC services was higher among urban residents (81.5\%), which corroborates to a study conducted in Holeta Town, Ethiopia where $86.7 \%$ of urban women used ANC services [27]. According to the Sierra Leone Demographic Survey (2019), 73.0\% of women in urban areas made 4 or more ANC visits which is slightly lower patronage as compared to our population. The high use of ANC services in urban areas may be because, Kailahun District has 87 peripheral health units and 3 hospitals, of which all the hospitals and most of the PHUs 
are in urban areas thus increasing access. Increased awareness and information sharing might also be related to the economic status of urban residents since women in urban areas have more physical and economic access to health facilities.

359 This research further indicated that the use of SDA was generally low. Only $35.9 \%$ of women 360 had at least one delivery in 3 years before this study used SDA compared to $11.7 \%$ in a study 361 in Ethiopia [5]. The majority, 57.6\%, and 4.2\% were delivered by Maternal and Child Health 362 Aide (MCHA) and Traditional Birth Attendant (TBA) respectively, who are considered nonskilled. According to the Demographic and Health Survey (2019), 87\% of deliveries were assisted by a skilled provider. The disparity between the DHS and this study may be related to the fact that our study did not consider MCHA and State Enrolled Community Health Nurses (SECHN) as a skilled attendant. Kailahun District is one of the most remote areas in Sierra Leone, physical accessibility is a major challenge due to the bad road network, thus most healthcare workers find it difficult to travel, work and stay in the district which creates opportunities for non-skilled workers. The WHO has recommended that there should be a critical threshold of 23 skilled healthcare workers (doctors, nurses, and midwives) per 10,000 population [28]. Nevertheless, it has been very difficult for Sierra Leone to cope with such recommendations due to the severe scarcity of qualified healthcare workers, thereby providing merely 2 skilled workers per 10,000 populations [29]. The 10 years of civil war which ended in 2002 and the 2014 Ebola epidemic, all started in Kailahun District and left a huge impact on health service delivery in the district. Sierra Leone is among the world's highest maternal death ratios at 1360 mortality per 100000 births [2] because most women are not delivered by a SDA, and most ANC services are provided by non-skilled providers. It further found that $10.5 \%$ and $35.9 \%$ of deliveries took place at Maternal and Child Health Post (MCHP) and Community Health Post (CHP) respectively, which are facilities manned by non-skilled attendants. 
This study found that the area of residence is a major determinant of SDA utilization. The use

382 of skilled birth attendants was higher among urban residents than rural. These findings are

383 consistent with other studies [5, 7]. The disparity in the utilization of MHC services may be

384 due to the concentration of health facilities in urban areas combined with the high number of

385 qualified birth attendants in urban areas and also the economic status of the urban residents. In

386 the Kailahun district, there is an uneven distribution of health workers, most are found in urban

387 areas. Distance to the health facility was considerably connected with the use of SDA. Women

388 that walked 30-60 minutes or more than 60 minutes to access health care services were more

389 likely to use SDA than those that walked less than 30 minutes. In another study conducted in

390 Kenya, although the distance was cited as a barrier to MHC service utilization, $18 \%$ of women

391 did not visit the nearest facility [30].

392 In the present study, the husband's education was significantly associated with the use of a

393 skilled delivery attendant. Women whose husbands had at least primary education were more

394 inclined to use SDA than those whose husbands had no education which is consistent with

395 other studies [5]. Similarly, in another study conducted in Nigeria, husbands education played

396 a key role in the utilization of SDA [1], research has shown that education increases health

397 awareness and knowledge on the significance of MHC services and improves other forms of

398 learning [5]. This could be through; radio, the internet, written information, and a better cultural

399 understanding. Educated husbands may provide more autonomy to their wives [5].

400 Our study found that the majority $97.5 \%$ of women received PNC services and $58.1 \%$ of them received it from MCHA. The 2013 Sierra Leone Demographic and Health Survey reported that $7.8 \%$ of PNC services were delivered by MCHA [12]. The disparity between the national and

403 district figures may be related to the fact that the Demographic Survey was done in the entire

404 16-district taking into consideration the major urban areas where good healthcare services are

405 concentrated compared with Kailahun being one of the most remote districts. Also, due to the 
406 limited number of skilled providers in the district, most PNC services are provided by a non-

407 skilled provider.

408 In the present study, women's residence, education of women, and husband's education are

409 significant predictors of the utilization of the standard PNC package. These observations are

410 consistent with a study conducted in Ethiopia among women of reproductive age which

411 reported a significant influence of respondent education and urban residence on the utilization

412 of MHC services [5].

413 Some of the respondents seemed to have difficulty in the recollection of events that had

414 happened during the last 3 years before the study. Women had difficulties in recalling or

415 identifying the nature of healthcare services they received or the trained healthcare worker that

416 provided the service. As a way of minimizing this challenge, the interviewers requested for

417 participants' ANC cards to fact-check their responses.

418 We did not assess the healthcare facility and the health workers' related-factors that affect

419 antenatal, postnatal, and skilled delivery utilization, all of which are known to be key

420 determinants of maternal health care utilization.

421

422

423

424

425

\section{CONCLUSION}

Our findings indicate that PNC service utilization in the Kailahun district is much higher compared to skilled ANC and birth attendant utilization, even though the uptake of the standard

426 PNC package was low. The utilization of SDA was low and urban residents seemed to be using more of the skilled birth attendant services. As recommended by WHO, the majority of women had 4 or more ANC visits, and most made their first ANC visit in the first trimester. Most of the deliveries were done by unskilled personnel. Education of women, residence, parity, 430 occupation, husband's education, and distance to health facility had a significant association 431 with the use of skilled birth attendants. Finally, the findings show that urban residence and 
432 higher/vocational education are significantly associated with the uptake of the standard PNC 433 package.

434 To improve the utilization of maternal health care services, the Ministry of Health and 435 Sanitation/Central Government should Work with relevant stakeholders to formulate policies 436 and design programs that target the advancement of education, rural infrastructure, and the 437 empowerment of women. The ministry of health should Engage the research and scientific 438 committee to undertake or facilitate further research programs to determine the healthcare 439 factors that influence the uptake of MHC services.

440

441 Abbreviations

442 ANC: Antenatal care

443 AOR: Adjusted odds ratio

444 CHC: Community health center

445 CHO: Community health officer

446 CHP: Community health post

447 CI: Confidence interval

448 COR: Crude odds ratio

449 DHS: Demographic and health survey

450 EAs: Enumeration areas

451 MCHA: Maternal and child health aide

452 MCHP: Maternal and child health post

453 MHCS: Maternal health care service

454 PNC: Postnatal care

455 PSU: Primary sampling unit

456 SDA: Skilled Delivery Attendant

457 
459 Ethical approval was sort from the Sierra Leone Ethics and Scientific Committee. Permission

460 was also sorted from the Kailahun Regional Health Directorate. Informed consent was sort

461 from the respondents. For respondents below 18 years, the accent was granted by the parent or

462 guardian. They were assured of confidentiality and informed on the purpose of the study. The

463 information was stored without the names of the respondents in a folder that is only accessible

464 to the research team. For participants who could not read, the consent was read and explained

465 to them in the presence of an impartial witness or stakeholder in the community. All study

466 methods were carried out in accordance with relevant guidelines and regulations

467

468 Consent for publication

469 Not applicable

470

$471 \quad$ Availability of data and materials

472 All data generated or analyzed during this study are included in this published article [ and its

473 supplementary information files]

474

475 Competing interest

476 The authors declare that they have no competing interest

477 Funding

$478 \quad$ Not applicable

479

480 Authors' contributions

481 Conceptualization and design: DMK, AAL, AM, EK, DAB

482 Data collection: DMK, JYK

483 Analysis and report writing: DMK, AAL, JYK 
484 Drafting manuscript: DMK, DAB, AM, JYK, AAL, EK

485 All authors read and approved the final manuscript.

486

487 Acknowledgment

488 My sincere gratitude goes to all staff of the Ministry of Health and Sanitation, Sierra Leone,

489 especially the former Chief Medical Officer Dr. Amara Jambai. I also wish to acknowledge the 490 respondents who took part in this study and also, the data collectors.

491

492

493

494

495

496

497

498 
500 Table 1 Enabling and predisposing characteristics of respondent who had at least one

501 delivery in the 3 years before the study, Kailahun District,Sierra Leone, 2020

\begin{tabular}{|c|c|c|}
\hline Predisposing/Enabling Characteristics & $\begin{array}{c}\text { Number } \\
(n=554)\end{array}$ & Percent $(\%)$ \\
\hline \multicolumn{3}{|l|}{ Age } \\
\hline $10-19$ & 76 & 13.7 \\
\hline $20-24$ & 172 & 31.0 \\
\hline $25-35$ & 254 & 45.8 \\
\hline$>35$ & 52 & 9.4 \\
\hline \multicolumn{3}{|l|}{ Schooling } \\
\hline No & 210 & 37.9 \\
\hline Yes & 344 & 62.1 \\
\hline \multicolumn{3}{|l|}{ Education level attainment } \\
\hline None & 210 & 37.9 \\
\hline Primary & 142 & 25.6 \\
\hline Junior Secondary & 142 & 25.6 \\
\hline Senior Secondary & 56 & 10.1 \\
\hline Vocational/Higher & 4 & 0.7 \\
\hline \multicolumn{3}{|l|}{ Religion } \\
\hline Christian & 217 & 39.2 \\
\hline Islam & 337 & 60.8 \\
\hline \multicolumn{3}{|l|}{ Ethnicity } \\
\hline Mende & 399 & 72.0 \\
\hline Kissi & 124 & 22.4 \\
\hline Others & 31 & 5.6 \\
\hline \multicolumn{3}{|l|}{ Number of Children Alive } \\
\hline $0-2$ & 275 & 49.6 \\
\hline $3-5$ & 231 & 41.7 \\
\hline $6+$ & 48 & 8.7 \\
\hline \multicolumn{3}{|l|}{ Parity } \\
\hline 1 & 132 & 23.8 \\
\hline $2-4$ & 292 & 52.7 \\
\hline $5+$ & 130 & 23.5 \\
\hline \multicolumn{3}{|l|}{ Number of Births in the past 5 years } \\
\hline 1 & 265 & 47.8 \\
\hline $2+$ & 289 & 52.2 \\
\hline \multicolumn{3}{|l|}{ Marital Status } \\
\hline Single & 37 & 6.7 \\
\hline Married/Living Together & 496 & 89.5 \\
\hline Divorced/separated/Widowed & 21 & 3.8 \\
\hline
\end{tabular}


Occupation

$\begin{array}{lrr}\text { Employed } & 433 & 78.2 \\ \text { Unemployed } & 121 & 21.8\end{array}$

Distance to Health Facility (Minutes)

$<30$

35.4

$30-60$

196

23.8

$>60$

132

40.8

Husband's Occupation

Unemployed

226

Employed

78

14.1

476

85.9

Husband's Education level attainment

None

238

43.0

Primary

72

13.0

Junior Secondary

109

19.7

Senior Secondary

82

14.8

Vocational/Higher

53

9.6

Residence

Rural

381

68.8

Urban

173

31.2

Type of Floor

Natural

394

71.1

Modern

160

28.9

Type of Toilet

Flush

14

2.5

Pit/Others

540

97.5 
517 Table 3 Socio-demographic characteristics and the use of MHC Services among women in

518 Kailahun District, Sierra Leone, 2020

\begin{tabular}{|c|c|c|c|c|}
\hline $\begin{array}{l}\text { Background } \\
\text { Characteristics }\end{array}$ & $\begin{array}{c}\text { Number } \\
(n=554)\end{array}$ & $\begin{array}{c}\text { Percentage } \\
\text { who received } \\
\text { at least one } \\
\text { ANC }\end{array}$ & $\begin{array}{l}\text { Percentage who } \\
\text { received SDA }\end{array}$ & $\begin{array}{c}\text { Percentage } \\
\text { who received } \\
\text { PNC services }\end{array}$ \\
\hline \multicolumn{5}{|l|}{ Age } \\
\hline $10-19$ & 76 & 76.3 & 42.1 & 97.4 \\
\hline $20-24$ & 172 & 77.9 & 36.1 & 98.3 \\
\hline $25-35$ & 254 & 76.4 & 35.4 & 97.2 \\
\hline$>35$ & 52 & 84.6 & 28.9 & 96.2 \\
\hline \multicolumn{5}{|l|}{ Residence } \\
\hline Urban & 173 & 81.5 & 57.8 & 96.5 \\
\hline Rural & 381 & 75.9 & 26 & 97.9 \\
\hline \multicolumn{5}{|l|}{ Marital Status } \\
\hline Single & 37 & 78.4 & 48.7 & 100 \\
\hline Married/Living Together & 496 & 77.2 & 34.7 & 97.2 \\
\hline Divorced/Separated/Widowed & 21 & 85.7 & 42.9 & 100 \\
\hline \multicolumn{5}{|l|}{ Religion } \\
\hline Christian & 217 & 79.7 & 37.3 & 98.6 \\
\hline Islam & 337 & 76.3 & 35 & 96.7 \\
\hline \multicolumn{5}{|l|}{ Ethnicity } \\
\hline Mende & 399 & 76.2 & 35.3 & 97.5 \\
\hline Kissi & 124 & 80.7 & 37.9 & 98.4 \\
\hline Others & 31 & 83.9 & 35.5 & 93.5 \\
\hline \multicolumn{5}{|l|}{ Parity } \\
\hline 1 & 132 & 79.6 & 43.2 & 97.7 \\
\hline $2-4$ & 292 & 77.4 & 37.3 & 97.9 \\
\hline $5+$ & 130 & 76.2 & 25.4 & 96.2 \\
\hline \multicolumn{5}{|l|}{ Occupation } \\
\hline Employed & 433 & 81.8 & 48.8 & 99.2 \\
\hline Unemployed & 121 & 76.4 & 32.3 & 97 \\
\hline \multicolumn{5}{|l|}{ Education level attainment } \\
\hline None & 210 & 78.6 & 30.9 & 96.7 \\
\hline Primary & 142 & 77.5 & 38 & 98.6 \\
\hline Junior Secondary & 142 & 71.8 & 33.8 & 96.5 \\
\hline Senior Secondary/Vocational & 60 & 88.3 & 53.3 & 100 \\
\hline \multicolumn{5}{|l|}{ Number of Births in the past 5 years } \\
\hline 1 & 265 & 80.4 & 39.6 & 97.7 \\
\hline $2+$ & 289 & 75.1 & 32.5 & 97.2 \\
\hline \multicolumn{5}{|l|}{ Husband's Occupation } \\
\hline Unemployed & 78 & 79.5 & 44.9 & 100 \\
\hline Employed & 476 & 77.3 & 34.5 & 97.1 \\
\hline \multicolumn{5}{|l|}{ Husband's Education level attainment } \\
\hline None & 238 & 75.2 & 30.3 & 97.9 \\
\hline Primary & 72 & 79.2 & 44.4 & 97.2 \\
\hline Junior Secondary & 109 & 80.7 & 37.6 & 98.2 \\
\hline
\end{tabular}


Senior Secondary

Vocational/Higher

Distance to Health Facility (Minutes)

$<30$

$30-60$

$>60$

Type of Floor

Natural

Modern

Type of Toilet

Flush

Pit and Others
82

53

78.1

79.3

196

132

226

394

160

14

540
77

75

79.7

77.4

78.1

85.7

77.4
30.5

54.7

97.6

94.3

35.7

96.4

47

98.5

97.8

29.7

34

40.6

97.2

98.1

35.7

100

35.9

97.4

519

520 
Table 4 Factors associated with the use of skilled delivery attendant, Kailahun District, Sierra

522 Leone, 2020

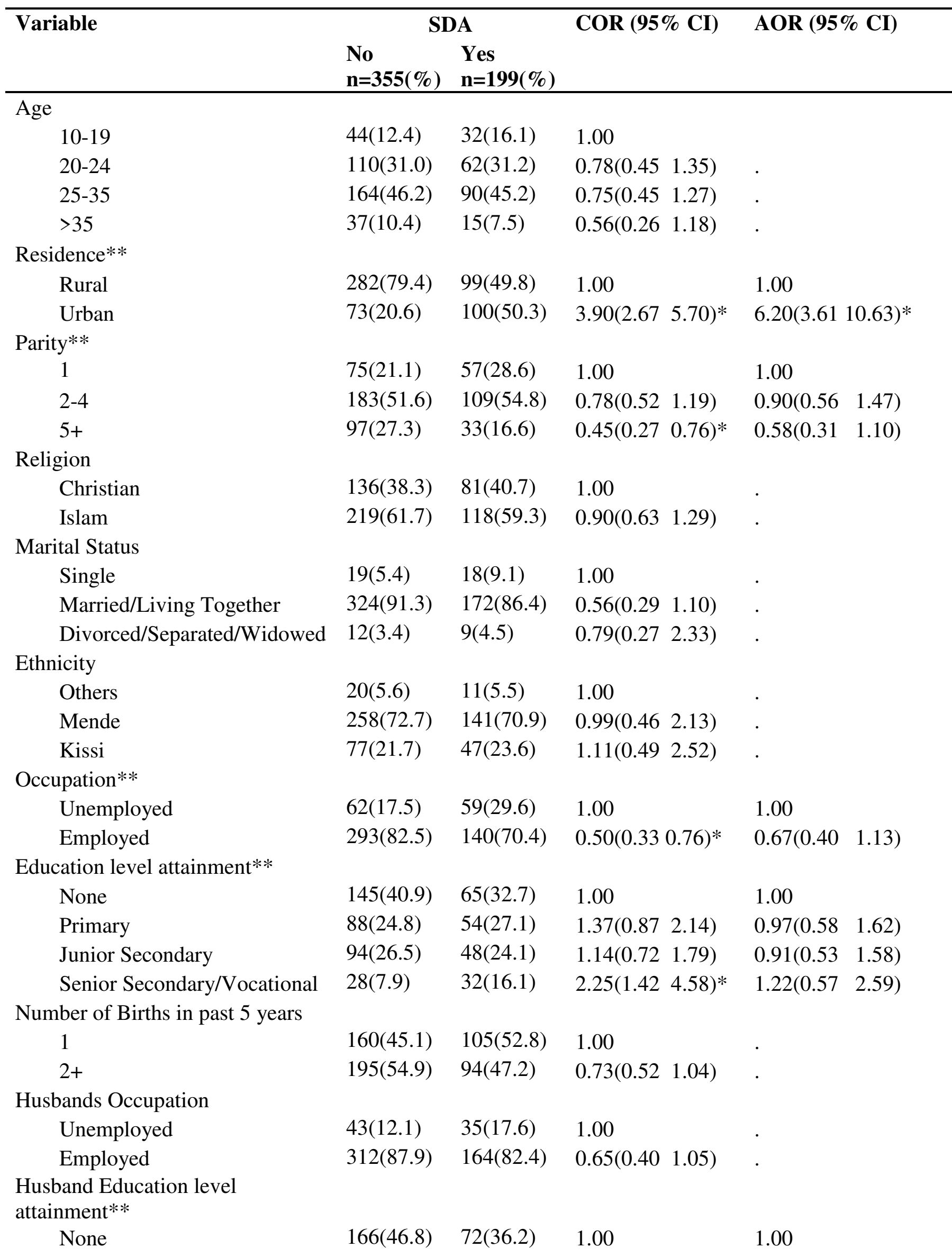




\begin{tabular}{|c|c|c|c|c|c|c|}
\hline Primary & $40(11.3)$ & $32(16.1)$ & $1.84(1.07$ & $3.17)^{*}$ & $2.38(1.30$ & $4.35)^{*}$ \\
\hline Junior Secondary & $68(19.2)$ & $41(20.6)$ & $1.39(0.86$ & 2.24) & $1.34(0.79$ & 2.29) \\
\hline Senior Secondary & $57(16.1)$ & $55(12.6)$ & $1.01(0.59$ & 1.74) & $0.67(0.35$ & $1.25)$ \\
\hline $\begin{array}{l}\text { Vocational/Higher } \\
\text { tance to Health Facility** } \\
\text { nutes) }\end{array}$ & $24(6.8)$ & $29(14.6)$ & $2.79(1.52$ & $5.11)^{*}$ & $1.85(0.93$ & $3.72)$ \\
\hline$<30$ & $126(35.5)$ & $70(35.2)$ & 1.00 & & 1.00 & \\
\hline $30-60$ & $70(19.7)$ & $62(31.2)$ & $1.59(1.02$ & $2.50)^{*}$ & $2.98(1.67$ & $5.33)^{*}$ \\
\hline$>60$ & $159(44.8)$ & $67(33.7)$ & $0.76(0.50$ & 1.14) & $2.37(1.33$ & $4.24)^{*}$ \\
\hline \multicolumn{7}{|l|}{ e of Floor } \\
\hline Natural & $260(73.2)$ & $134(67.3)$ & 1.00 & & . & \\
\hline Modern & $95(26.8)$ & $65(32.7)$ & $1.33(0.91$ & 1.94) & . & \\
\hline \multicolumn{7}{|l|}{ e of Toilet } \\
\hline Pit and Others & 346(97.5) & 194(97.5) & 1.00 & & . & \\
\hline Flush & $9(2.5)$ & $5(2.5)$ & $0.99(0.33$ & $3.00)$ & & \\
\hline
\end{tabular}


527 [1] O. Ovikuomagbe, "Determinants of Maternal Healthcare Utilization in Nigeria," vol. 11, no. 46, pp. 2006-2017, 2017.

529 [2] WHO, "Sierra Leone Annual Report 2017," Freetown, 2017.

530 [3] L. Cameron, D. C. Suarez, and K. Cornwell, "Understanding the determinants of maternal mortality: An observational study using the Indonesian Population Census," PLoS One, vol. 14, no. 6, pp. 1-18, 2019.

[4] W. Ju Hwang and Y. Mi Park, "Factors influencing the accessibility of maternal health service in Cambodia," Int. J. Environ. Res. Public Health, vol. 16, no. 16, Aug. 2019.

[5] S. M. Tarekegn, L. S. Lieberman, and V. Giedraitis, "Determinants of maternal health service utilization in Ethiopia: analysis of the 2011 Ethiopian Demographic and Health Survey," BMC Pregnancy Childbirth, pp. 1-13, 2014.

[6] D. Zelalem Ayele, B. Belayihun, K. Teji, and D. Admassu Ayana, "Factors Affecting Utilization of Maternal Health Care Services in Kombolcha District, Eastern Hararghe Zone, Oromia Regional State, Eastern Ethiopia,” Int. Sch. Res. Not., vol. 2014, pp. 1$7,2014$.

[7] G. Rutaremwa, S. O. Wandera, T. Jhamba, E. Akiror, and A. Kiconco, "Determinants of maternal health services utilization in Uganda," BMC Health Serv. Res., vol. 15, no. 1, pp. 1-8, 2015.

[8] U. Haruna, G. Dandeebo, and S. Z. Galaa, "Improving Access and Utilization of Maternal Healthcare Services through Focused Antenatal Care in Rural Ghana: A Qualitative Study," Adv. Public Heal., vol. 2019, pp. 1-11, Jul. 2019.

[9] G. A. Fekadu, F. Ambaw, and S. A. Kidanie, "Facility delivery and postnatal care services use among mothers who attended four or more antenatal care visits in Ethiopia: Further analysis of the 2016 demographic and health survey," BMC Pregnancy Childbirth, vol. 19, no. 1, p. 64, Feb. 2019. 
[10] A. A. Ewunetie, A. M. Munea, B. T. Meselu, M. M. Simeneh, and B. T. Meteku, "DELAY on first antenatal care visit and its associated factors among pregnant women in public health facilities of Debre Markos town, North West Ethiopia," BMC Pregnancy Childbirth, vol. 18, no. 1, p. 173, May 2018.

[11] M. Boah, A. B. Mahama, and E. A. Ayamga, "They receive antenatal care in health facilities, yet do not deliver there: Predictors of health facility delivery by women in rural Ghana,” BMC Pregnancy Childbirth, vol. 18, no. 1, p. 125, May 2018.

[12] DHS, "Demographic and Health Survey," 2013.

[13] WHO, "Maternal mortality.," J. Ky. Med. Assoc., vol. 81, no. 10, pp. 799-801, 2017.

[14] W. B. G. and the U. N. P. D. WHO UNICEF, UNFPA, “Trends in Maternal Mortality: 1990 to $2015, " 2015$.

[15] World Health Organisation, "Maternal Health | WHO | Regional Office for Africa," Regional office for Africa, 2020. [Online]. Available: https://www.afro.who.int/healthtopics/maternal-health. [Accessed: 11-Jan-2021].

[16] Statistics Sierra Leone, "Statistics Sierra Leone 2015 Population and Housing Census Summary of Final Results," pp. 1-190, 2015.

[17] Statistics Sierra Leone, "Sierra Leone 2015. Polulation and Housing Census. Thematic Report on Population Projections,”vol. 296, no. 7672, p. 563, 2015.

[18] W. G. Cochran, "Sampling Techniques, third edition," Therapeutic Drug Monitoring and Toxicology by Liquid Chromatography. pp. 1-500, 1977.

[19] R. Andersen and L. A. Aday, “Access to medical care in the U.S.: Realized and potential," Med. Care, vol. 16, no. 7, pp. 533-546, 1978.

[20] R. Andersen and J. F. Newman, "Societal and individual determinants of medical care utilization in the United States," Milbank Q., vol. 83, no. 4, 2005.

[21] B. H. Kehrer, R. Andersen, and W. A. Glaser, “A Behavioral Model of Families’ Use of Health ServicesPaying the Doctor: Systems of Remuneration and Their Effects," $J$. 
Hum. Resour., vol. 7, no. 1, p. 125, 1972.

579 [22] Uganda Bureau of Statistics, "GOVERNMENT OF UGANDA Uganda Demographic $580 \quad$ and Health Survey 2016," Udhs 2016, p. 625, 2016.

581 [23] WHO, "WHO,” 2019.

582 [24] K. Birmeta, Y. Dibaba, and D. Woldeyohannes, "Determinants of maternal health care 583 utilization in Holeta town, central Ethiopia,” pp. 1-10, 2013.

584 [25] WHO, “Achieving the health-related MDGs .It takes a workforce!,” WHO, p. 2, 2010.

585 [26] Directorate of Reproductive \& Child health, "MATERNAL DEATH SURVEILLANCE AND RESPONSE,” 2016.

587 [27] A. M. Van Eijk et al., "Use of antenatal services and delivery care among women in 588 rural western Kenya: A community based survey," Reprod. Health, vol. 3, pp. 1-9, 2006.

590 


\section{Supplementary Files}

This is a list of supplementary files associated with this preprint. Click to download.

- File1.Dataset.xlsx 